\title{
Cyclic Voltammograms from First Principles
}

Karlberg, Gustav; Jaramillo, Thomas; Skulason, Egill; RossmeisI, Jan; Bligaard, Thomas; Nørskov, Jens Kehlet

\section{Published in:}

E C S Transactions

Link to article, DOI:

10.1149/1.2780988

Publication date:

2007

Document Version

Publisher's PDF, also known as Version of record

Link back to DTU Orbit

Citation (APA):

Karlberg, G., Jaramillo, T., Skulason, E., Rossmeisl, J., Bligaard, T., \& Nørskov, J. K. (2007). Cyclic

Voltammograms from First Principles. E C S Transactions, 11(1), 759-768. https://doi.org/10.1149/1.2780988

\section{General rights}

Copyright and moral rights for the publications made accessible in the public portal are retained by the authors and/or other copyright owners and it is a condition of accessing publications that users recognise and abide by the legal requirements associated with these rights.

- Users may download and print one copy of any publication from the public portal for the purpose of private study or research.

- You may not further distribute the material or use it for any profit-making activity or commercial gain

- You may freely distribute the URL identifying the publication in the public portal

If you believe that this document breaches copyright please contact us providing details, and we will remove access to the work immediately and investigate your claim. 


\title{
Cyclic Voltammetry from First-Principles
}

\author{
G. S. Karlberg ${ }^{\mathrm{a}}$, T. F. Jaramillo ${ }^{\mathrm{b}}$, E. Skulason ${ }^{\mathrm{a}}$, J. Rossmeisl ${ }^{\mathrm{a}}$, T. Bligaard ${ }^{\mathrm{a}}$ and J. K. \\ Nørskov $^{\mathrm{a}}$ \\ ${ }^{a}$ Center for Atomic-scale Materials Design, Department of Physics, Technical University \\ of Denmark, DK-2800 Kgs. Lyngby, Denmark \\ ${ }^{\mathrm{b}}$ Center for Individual Nanoparticle Functionality, Department of Physics, Technical \\ University of Denmark, DK-2800 Kgs. Lyngby, Denmark
}

Cyclic voltammetry is a fundamental experimental tool for characterizing electrochemical surfaces. Whereas cyclic voltammetry is widely used within the field of electrochemistry, a way to quantitatively and directly relate the cyclic voltammogram to ab initio calculations has been lacking, even for the simple case of electroadsorption and desorption of $\mathrm{H}$. In the following we derive the cyclic voltammogram for $\mathrm{H}$ adsorption and desorption on $\operatorname{Pt}(111)$ and $\operatorname{Pt}(100)$ based solely on density functional theory calculations and standard molecular tables. The method will also be extended to include the potential dependence of the $\mathrm{OH}$ coverage during electrochemical water splitting on $\operatorname{Pt}(111)$ and $\mathrm{Pt}_{3} \mathrm{Ni}(111)$.

\section{Introduction}

Cyclic voltammetry is perhaps the most important and widely utilized technique in the field of analytical electrochemistry. This method provides an abundance of quantitative information regarding surface electrochemical phenomena, including the adsorption/desorption of species such as $\mathrm{H}^{*}$ and $\mathrm{OH}^{*}$, reduction/oxidation of the electrode surface, reduction/oxidation of dissolved analytes (for example, $\mathrm{Fe}^{2+} / \mathrm{Fe}^{3+}$ ), as well as electrocatalytic turnover (for example, $\mathrm{H}_{2}$ evolution or $\mathrm{O}_{2}$ reduction). Many general and specific mathematical relationships have been developed to describe spectra recorded using cyclic voltammetry $(1,2,3,4,5,6,7,8)$. Such expressions are crucial in the interpretation of measured data; however, a direct connection between the density functional theory calculations and the electrode potential has been lacking.

In recent years, much electrochemical research has been directed toward the discovery of new materials (mostly alloys) for improved catalysis of energy conversion reactions, such as those ubiquitous in fuel cells or electrolyzers. It has been well-established that catalytic activity is directly related to the adsorption/desorption of reaction intermediates on the catalyst surface $(9,10)$. As cyclic voltammetry provides such information, for instance adsorption of $\mathrm{H}^{*}$ in the case of $\mathrm{H}_{2}$ evolution and $\mathrm{OH}^{*}$ and/or $\mathrm{O}_{2}^{*}$ in the case of $\mathrm{O}_{2}$ reduction, the ability to predict such behavior on new materials as a function of electrode potential would be of tremendous benefit for electrocatalyst discovery.

Herein, we present theoretical cyclic voltammograms of archetypical $\operatorname{Pt}(111)$ and $\operatorname{Pt}(100)$ in the region of hydrogen under-potential deposition (H-UPD), produced solely from Density Functional Theory (DFT) calculations and standard molecular tables. The 
theoretical CVs show excellent agreement with those measured experimentally, indicating that predicting CVs behavior on new materials is a tangible goal that could be realized in the not-too-distant future. The method will also be extended to include cyclic voltammograms for water dissociation on $\mathrm{Pt}(111)$ and $\mathrm{Pt}_{3} \mathrm{Ni}(111)$. Also in this case the agreement with experiments is excellent. This good agreement with experimental measurements provides further support for the underlying theoretical framework for describing electrochemical reactions (11), and also opens up for a stronger connection between experiment and theory.

\section{Methods}

The density functional theory calculations are performed using a plane-wave pseudopotential implementation $(12,13)$ employing the ultra-soft pseudopotentials of Vanderbilt (14) to represent the ionic cores. For all calculations the RPBE (15) flavor of the exchange and correlation functional has been used. Three and four layer thick periodic $2 \times 2$ supercells were used for to represent the $\operatorname{Pt}(111)$ and $\operatorname{Pt}(100)$ surfaces, respectively, all at the RPBE lattice constant of Pt (4.02 $\AA$ ). For Pt(111) a $2 \times 3$ cell with three layers was also used. In all cases the bottom two layers were kept fix while the top layers were allowed to relax. The plane wave cutoff was $26 \mathrm{Ry}$, and the k-points were sampled using a $4 \times 4 \times 1$ and $4 \times 6 \times 1$ Monkhorst-Pack reduced grids. Dipole correction was used in all cases. Based on the DFT results a lattice model is developed for the $\mathrm{H}-\mathrm{H}$ interaction. We solve the lattice model by use of standard Metropolis Monte Carlo calculations (16).

In order to construct a theoretical $\mathrm{CV}$ for $\mathrm{H}$ adsorption a theoretical counterpart to the standard hydrogen electrode (SHE) needs to be established. A method to do that has been presented previously (11), and it will be summarized here for clarity. Consider the following two reactions:

$$
\begin{gathered}
1 / 2 H_{2}(g) \rightarrow H^{+}+e^{-} \\
H^{+}+e^{-} \rightarrow H^{*}
\end{gathered}
$$

where $H^{*}$ refers to $\mathrm{H}$ adsorbed on the surface. At the conditions used to establish the standard hydrogen electrode potential, $\mathrm{T}=300 \mathrm{~K}, \mathrm{p}_{\mathrm{H}_{2}}=1 \mathrm{bar}$ and $\mathrm{pH}=0$, the reaction free energies of all these reactions are zero. Consequently, the free energies of all three states, $1 / 2 H_{2}(g),\left(H^{+}+e^{-}\right)$, and $H^{*}$ are equal. This defines $U=0 \mathrm{~V}$. At another potential the chemical potential of the electrons $e^{-}$is changed by $-e U$ with respect to $H_{2}$ in the gas phase. For the conditions applicable for this investigation it is reasonable to assume that reaction [2] quickly reaches equilibrium. Hence, the reaction free energy of reaction [2] can be obtained by the Born-Haber cycle: $H^{+}+e^{-} \rightarrow 1 / 2 H_{2}(g) \rightarrow H^{*}$. Adding the changes in free energy during this cycle we obtain the following reaction free energy for reaction [2],

$$
\Delta G(U)=\Delta G_{0}+e U
$$

where $\Delta G_{0}$ is the free energy of reaction for 


$$
1 / 2 H_{2}(g) \rightarrow H^{*}
$$

at standard conditions. This free energy can be directly calculated using DFT and standard molecular tables via

$$
\Delta G_{0}=\Delta E+\Delta Z P E-T \Delta S .
$$

Here $\triangle E$ and $\triangle Z P E$ are the differential adsorption energy for $\mathrm{H}$ and the difference in zero point energy for reaction [4] as given by DFT. $\Delta S$ is the difference in entropy. At a $\mathrm{pH}$ different from zero the entropy for the $H^{+}$ion will change. Expression [5] can be corrected for that by adding $G(p H)=-k_{B} T \ln \left[H^{+}\right]=k_{B} T \cdot p H$.

The effect of the surrounding water and the presence of a local electric field (i.e. the electric double layer) on the differential adsorption energy of $\mathrm{H}$ will be taken into account explicitly in the DFT calculations that follow.

The $\Delta G_{0}$ defined above will depend on the coverage, $\theta$, of hydrogen. The dependence arises both because of the direct $\mathrm{H}-\mathrm{H}$ interaction between the adsorbed $\mathrm{H}$ atoms, and via the dependence on coverage for the configurational entropy of the adsorbed $\mathrm{H}$ atoms. Assuming that the adsorbed hydrogen atoms on the surface are always in equilibrium with the protons in the solution, i.e. that $\Delta G(U)=0$, we obtain:

$$
U(\theta)=-\Delta G_{0}(\theta) / e .
$$

The way this equality can be maintained is by changing the coverage of adsorbed $\mathrm{H}$. Hence, from the reactions above we can extract the equilibrium coverage of $\mathrm{H}$ on the surface as a function of potential. This in turn can be directly related to the current measured in a cyclic voltammogram as will be shown below.

Cyclic voltammetry entails the measurement of current flowing through an electrode during a linear sweep of its potential versus a known electrochemical reference, such as the standard hydrogen electrode. The resulting electrochemical "spectrum" is comprised of features produced by both Faradaic processes, associated with electron transfer, and non-Faradaic processes, associated with charging of the electrical double-layer. The features emerge at the potentials in which such processes occur, while the measured current reflects the net rate of all processes occurring at that potential. In the following we will contruct a theoretical $\mathrm{CV}$ which only concerns $\mathrm{H}$ adsorption and desorption. Our starting point is the derivative of $U$ with respect to time:

$$
\frac{d U}{d t}=\frac{d U}{d \theta} \cdot \frac{d \theta}{d Q} \cdot \frac{d Q}{d t}
$$

Here Error! is the linear sweep rate of the experiment and Error! is the measured current. With a transfer of one electron per adsorbed $\mathrm{H}$, the relation between the charge transferred per area $Q$ and the coverage $\theta$ is $Q=Q_{t o t} \cdot \theta$. Here $Q_{\text {tot }}$ is $e$ times the density of 
Pt atoms in the surface layer. Introducing $\pm K$ for the sweep rate and $i(t)$ for the current we obtain:

$$
i(t)= \pm K Q_{t o t} \frac{1}{\frac{d U}{d \theta}}= \pm K Q_{t o t} \frac{d \theta}{d U}
$$

$\underline{\mathrm{H} \text { on } \mathrm{Pt}(111) \text { and } \mathrm{Pt}(100)}$

\section{Results}

Using DFT we have calculated the differential adsorption energy for $\mathrm{H}$ on $\mathrm{Pt}(111)$ and $\operatorname{Pt}(100)$, see Figure 1. To test the effect of a water surrounding and an electric field we have calculated the differential adsorption energy for $\mathrm{H}$ both with out water and with water and electric field. As can be seen from part (a) of Figure 1, the effect of water and electric field is negligible. This minor effect of water and electric field on $\mathrm{H}$ adsorption has been observed previously (17).

For a coverage up to 1 monolayer (ML) on Pt(111) the three fold hollow FCC site is the most stable. For a higher coverage the one-fold ontop site is most stable. On Pt(100) the two-fold bridge site is the most stable both at below and slightly above 1 monolayer coverage. Here one monolayer corresponds to $1 \mathrm{H}$ atom per surface Pt atom.

An important feature to note in part (a) of Figure 1 is the jump in $\Delta \mathrm{E}$ as the coverage becomes larger than 1 . This jump is due to the increased $\mathrm{H}-\mathrm{H}$ interaction when a new high symmetry site becomes occupied at a coverage above 1 ML. A similar but less pronounced jump can be observed for the $\mathrm{Pt}(100)$ surface (not shown), where $\Delta \mathrm{E}$ goes from $-0.43 \mathrm{eV}$ at $1 \mathrm{ML}$ to $-0.19 \mathrm{eV}$ at $1.25 \mathrm{ML}$. The potentials at which these states would become occupied roughly corresponds to $+0.4 \mathrm{~V}$ and $0.0 \mathrm{~V}$ for the $\operatorname{Pt}(111)$ and $\mathrm{Pt}(100)$ surfaces. Hence, in the analysis that follows the $\mathrm{H}$ coverage will be less than or equal to 1 monolayer.

The first step towards generating a $\mathrm{CV}$ is to obtain the coverage of $\mathrm{H}$ as a function of potential. Assuming a charge transfer of one electron per Hydrogen atom the coverage can immediately be transformed to surface charge density. We obtain the coverage versus voltage graph by using the free energy of adsorption given by equation [3] in a Metropolis Monte Carlo simulation (16). In this simulation a $\mathrm{H}$ atom is adsorbed/desorbed from an empty/filled site if $\Delta \mathrm{G}(\mathrm{U})$ for that process is negative. If the $\Delta \mathrm{G}$ for that process positive it can still occur with a probability proportional to $\exp (-$ $\left.\Delta \mathrm{G}(\mathrm{U}) / \mathrm{k}_{B} \mathrm{~T}\right)$. The local differential adsorption energy is evaluated using a lattice model and a model Hamiltonian. We use a simple model Hamiltonian including only pairwise nearest neighbor interaction: 


$$
\Delta E=\Delta E_{0}+\sum_{i} J \sigma_{i}
$$

where $\Delta E_{0}$ is the differential heat of adsorption without any nearest neighbors, $J$ is the interaction parameter and $\sigma_{i}$ is an occupation number. As can be seen from part (b) of Figure 1 the $\mathrm{H}-\mathrm{H}$ interaction is to a high accuracy described a pair-wise nearest neighbor interaction on both $\operatorname{Pt}(111)$ and $\operatorname{Pt}(100)$.

Another less rigorous but more simple and transparent way to make the $\mathrm{CV}$ is to express the differential adsorption energy $\Delta \mathrm{E}$ as a function of coverage, see part part (c) of Figure 1. It turns out that the DFT data points to a quite good approximation can be fitted to a straight line. Before plugging this into the method outlined above, equation [5] needs to be corrected for the configurational entropy, which in the case of the Metropolis method was included a priori. We include this by adding the differential configurational entropy of non-interacting particles,

$$
\Delta S_{\text {conf }}=k_{B} \ln \left(\frac{1-\theta}{\theta}\right)
$$

to equation [5]. This modified free energy is then differentiated to give:

$$
\frac{d U}{d \theta}=-\frac{1}{e}\left(a+k_{B} T \frac{1}{\theta(1-\theta)}\right)
$$

where $a$ is the slope of the $\Delta \mathrm{E}(\theta)$ curve in Figure 1 (b). Combining equation [11] with equation [8] one clearly sees how both the $\mathrm{H}-\mathrm{H}$ interaction, and the configurational entropy affects the $\mathrm{CV}$ curve for $\mathrm{H}$ adsorption and desorption. Although explicit use of equation [11] requires a numeric inversion of the $U(\theta)$ function, it is henceforth termed "analytic" to distinguish it from the Monte Carlo approach.

In the parts (a) and (b) of Figure 2 the results of the Metropolis and analytic simulations are shown for $\mathrm{T}=274 \mathrm{~K}$. Part (c) and (d) show the corresponding cyclic voltammogram for a sweep rate of $50 \mathrm{mV} / \mathrm{s}$. Finally, part (e) and (f) show the temperature dependence of the $\mathrm{CV}$ peaks as given by the Metropolis algorithm. Whereas experimental measurements of the $\mathrm{CV}$ for $\mathrm{H}$ adsorption and desorption can be found in many references since the pioneering work by Clavilier $(18,19)$ we chosen to simulate the $\mathrm{CVs}$ for the temperatures presented in an investigation by Markovic and co-workers (20).

The agreement with experiments very good. For both $\operatorname{Pt}(111)$ and $\operatorname{Pt}(100)$ the charge versus potential curves, and the $\mathrm{i}-\mathrm{V}$ characteristics are quite similar to the experimental ones presented in ref. (20). Also the experimental temperature dependence is reproduced. However, our model does not include hydrogen evolution, and hence we do not reproduce the region below about $+0.05 \mathrm{~V}$ where the experimental current is dominated by the hydrogen evolution current. Another difference compared to experiments concerns features related to the anions of the electrolyte. Whereas several authors have made models for this on the $\operatorname{Pt}(111)$ surface $(4,21)$ we here focus only on the adsorption or 
desorption of $\mathrm{H}$, which can be directly related to first-principles calculations. Finally, we do not model the capacitance of the electric double layer. Hence, our model predicts zero current when there is no adsorption or desorption of $\mathrm{H}$ from the surface.
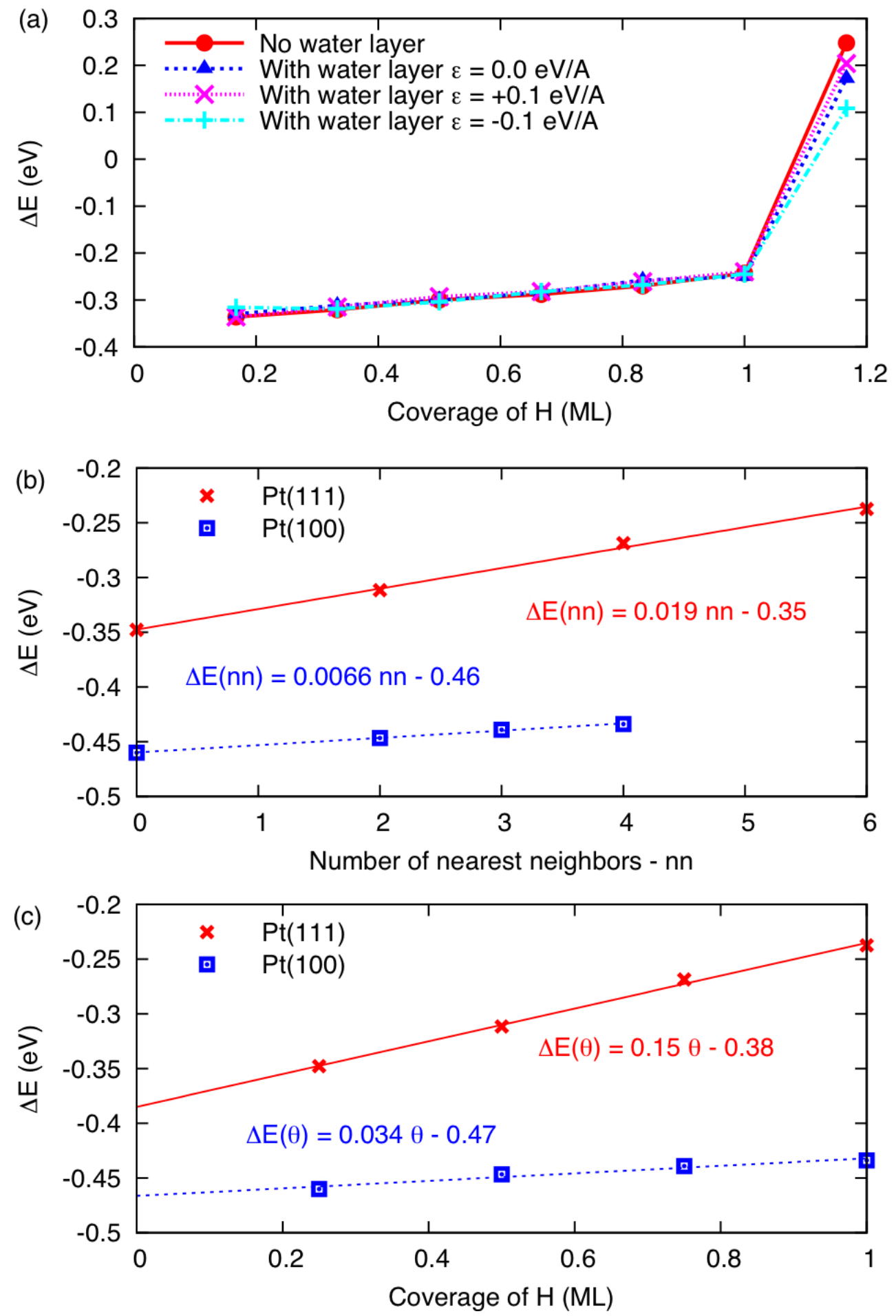

Figure 1. Differential adsorption energy $\Delta \mathrm{E}$ for $\mathrm{H}$ on $\mathrm{Pt}(111)$ and $\mathrm{Pt}(100)$. Part (a) shows the effect of a water bilayer and electric field for the $\operatorname{Pt}(111)$ electrode. In parts (b) and (c) $\Delta \mathrm{E}$ is plotted versus the number of $\mathrm{H}$ nearest neighbors on the surface and the $\mathrm{H}$ coverage, respectively. 


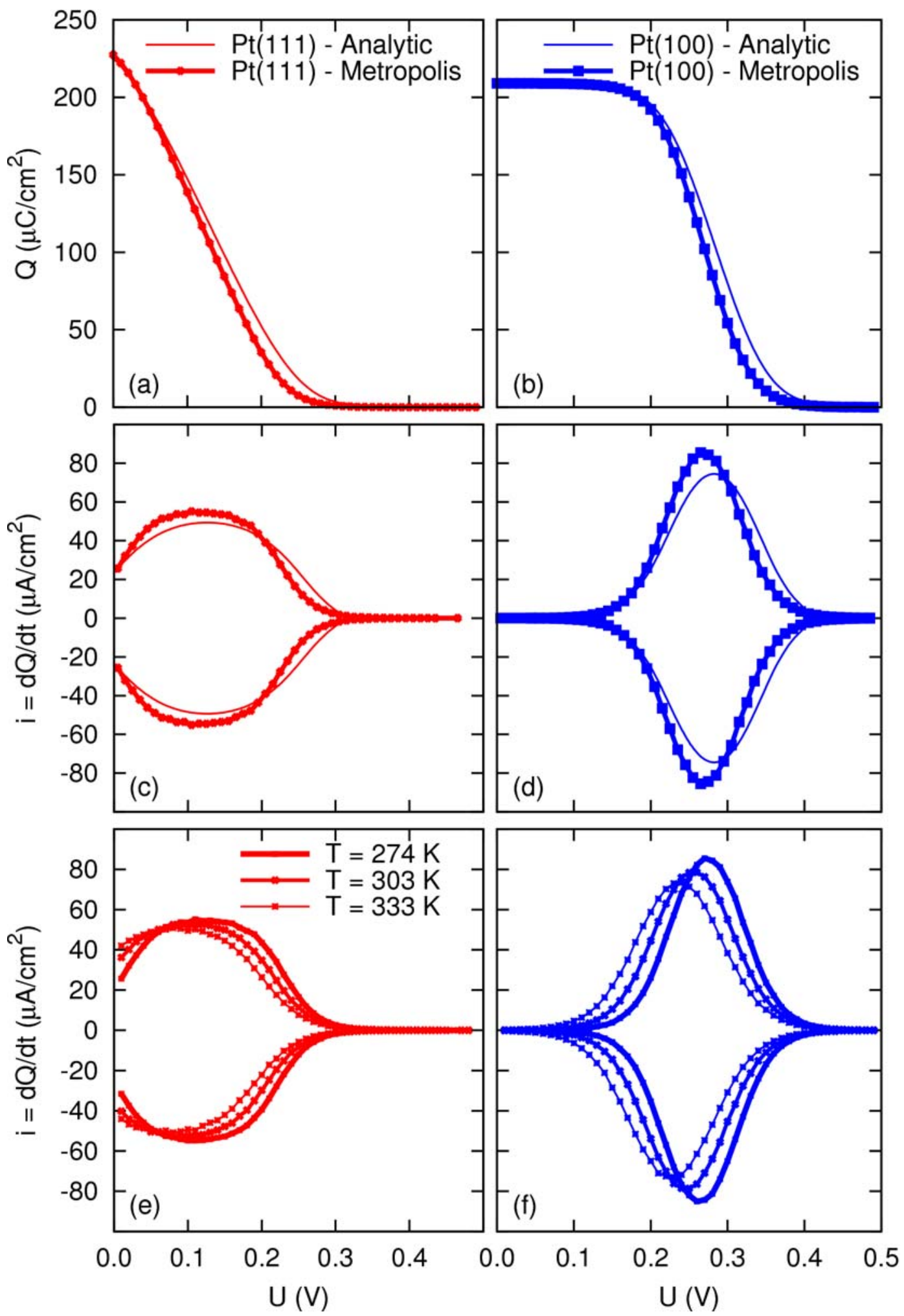

Figure 2: Charge deposition due to hydrogen adsorption versus potential ((a),(b)) and theoretical cyclic voltammograms for $\operatorname{Pt}(111)((\mathrm{c}),(\mathrm{e}))$ and $\mathrm{Pt}(100)((\mathrm{d}),(\mathrm{f}))$. The CVs are based solely on input from standard tables of gas phase molecules and output from density functional theory. In the figure results are shown both from Monte Carlo 
calculations where all interactions are taken into account, and an analytical model where the entropy is that of non interacting particles.

\section{$\underline{\mathrm{OH}}$ on $\mathrm{Pt}(111)$ and $\mathrm{Pt}_{3} \underline{\mathrm{Ni}(111)}$}

Having established this methodology another interesting case to study with great relevance for fuel cell engineering is oxygen reduction on $\mathrm{Pt}(111)$ and $\mathrm{Pt}_{3} \mathrm{Ni}(111)$. This system has recently been studied both experimentally $(22,23,24)$ and theoretically $(24)$. Since there are experimental data for the $\mathrm{OH}$ coverage versus electrode potential during electrochemical water splitting on these systems (24), we will not proceed all the way to the $\mathrm{CV}$ in this case. To calculate the $\mathrm{OH}$ coverage versus electrode potential we need to consider the reaction:

$$
\mathrm{H}_{2} \mathrm{O} \rightarrow \mathrm{OH}^{*}+\mathrm{H}^{+}+e^{-}
$$

On these surfaces the excess barrier for this reaction is most probably small since the reaction appears to be totally reversible from CVs in both acid and alkaline solutions on $\mathrm{Pt}(111)$ (20). To simplify the analysis we will assume that the adsorbed $\mathrm{OH}$ molecules does not interact with each other. This assumption is motivated since a mixed $\mathrm{OH}-\mathrm{H}_{2} \mathrm{O}$ structure will be formed during water dissociation, where $\mathrm{OH}$ molecules will not be nearest neighbors $(11,25)$. Furthermore, we will assume that the coverage will not exceed $1 / 3$ of a monolayer of $\mathrm{OH}$. The reason being that at a higher coverage $\mathrm{OH}$ molecules will indeed be neighbors. Since the hydrogen bond strength between $\mathrm{OH}$ molecules is less than half of that between an $\mathrm{OH}$ molecule and $\mathrm{H}_{2} \mathrm{O}$ molecule (25), the $\mathrm{OH}-\mathrm{OH}$ neighbor situation would give rise to an equivalent to the step in reaction energy as was observed for a $\mathrm{H}$ coverage larger than 1 monolayer, see part (a) of Figure 1 . Under the above assumptions, and based on the methodology above we can write the potential dependence of the $\mathrm{OH}$ coverage as:

$$
\theta(U)=\frac{1}{3} \cdot \frac{1}{1+\exp (\Delta G-e U)}
$$

In the above expression a maximum $\mathrm{OH}$ coverage of $1 / 3$ of a monolayer has been assumed. From ref. (24) one can obtain the $\Delta \mathrm{G}$ values for $\mathrm{OH}$ adsorption to be $0.80 \mathrm{eV}$ and $0.93 \mathrm{eV}$ for $\mathrm{Pt}(111)$ and $\mathrm{Pt}_{3} \mathrm{Ni}(111)$, respectively. Inserting these numbers into equation [13] a graph of the $\mathrm{OH}$ coverage versus $\mathrm{U}$ can be constructed, see Figure 3. As can be seen the agreement is excellent also in this case. 


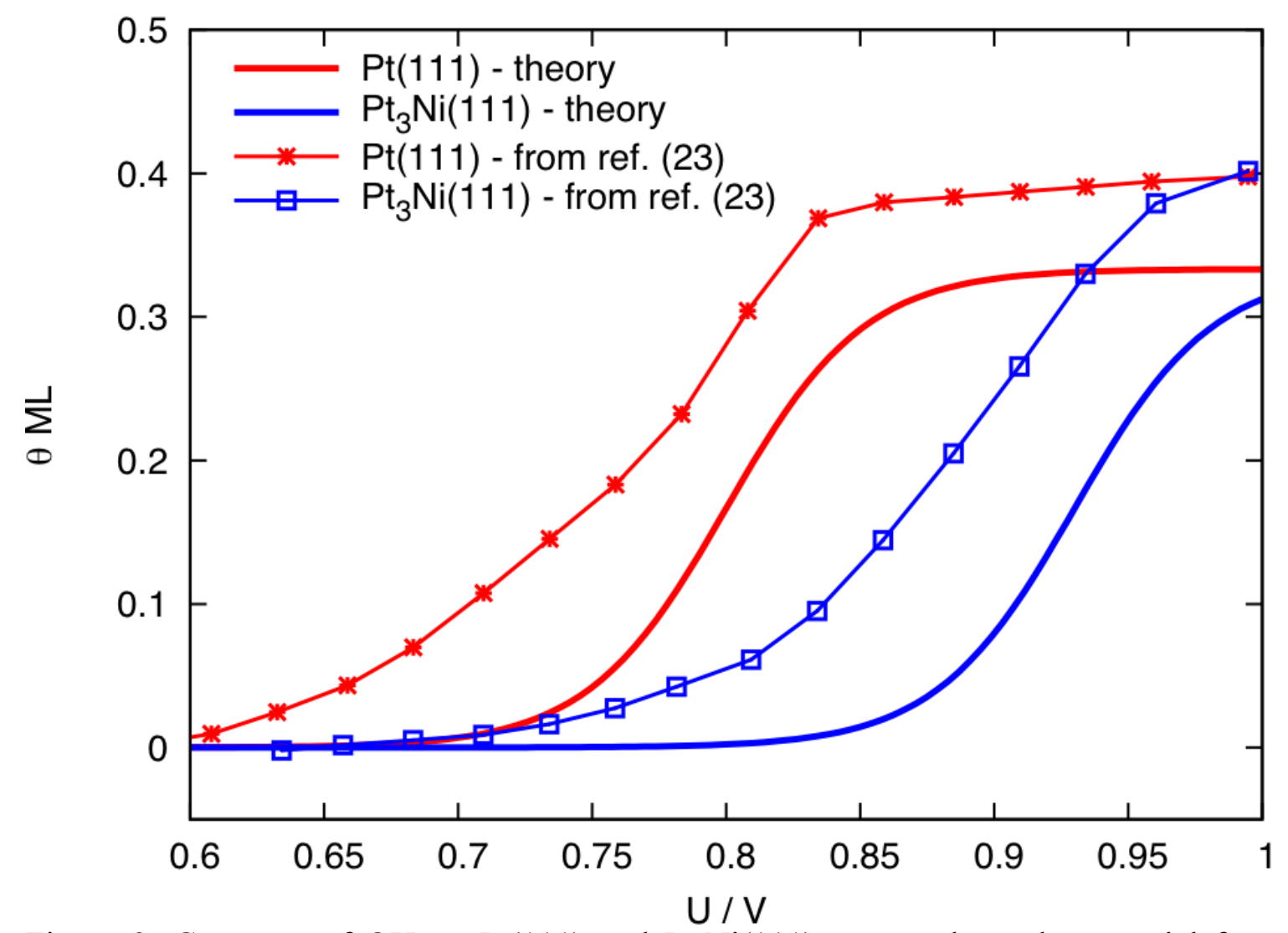

Figure 3: Coverage of $\mathrm{OH}$ on $\mathrm{Pt}(111)$ and $\mathrm{Pt}_{3} \mathrm{Ni}(111)$ versus electrode potential from theory (equation [13]) and experiments reported in ref. (23).

\section{Summary}

In this paper a methodology to calculate cyclic voltammograms directly from density functional theory calculations and molecular tables have been presented. The first test case was $\mathrm{H}$ adsorption on $\operatorname{Pt}(111)$ and $\operatorname{Pt}(100)$. The agreement with experiments is excellent. The same method was also tested against recent experimental data for the potential dependence of the $\mathrm{OH}$ coverage during electrochemical water dissociation on $\mathrm{Pt}(111)$ and $\mathrm{Pt} 3 \mathrm{Ni}(111)$. Even for this case the agreement is very good. This indicates that we now have a direct link between adsorption energies, as for instance obtained from density functional theory calculations, and cyclic voltammograms.

\section{Acknowledgments}

This work was supported by the Danish Research Council for the Technical Sciences and the European Community program FCANODE. The Danish Center for Scientific Computing contributed funding for the computer time.

\section{References}

1. J. O. M. Bockris and S. U. M. Khan. Surface electrochemistry. Plenum press, (1993). 
2. R. Greef, R. Peat, L. M. Peter, D. Pletcher, and J. Robinson. Instrumental methods in electrochemistry. Ellis Horwood, (1990).

3. L. Blum, D. A. Huckaby, N. Marzari, and R. Car., J. Electroanal. Chem., 537, 7 (2002).

4. M. T. M. Koper and J. J. Lukkien,. J. Electroanal. Chem., 485, 161 (2000).

5. N. P. Lebedeva, M. T. M. Koper, E. Herrero, J. M. Feliu, and E. A. van Santen, Angew. Chem. Int. Ed., 487, 37 (2000).

6. P. A. Rikvold, J. Zhang, Y. E. Sung, and A. Wieckowski., Electrochim. Acta., 41, 2175 (1996).

7. L. Blum, D. A. Huckaby, and M. Legault., Electrochim. Acta, 41, 2207 (1996).

8. G. Jerkiewicz. Progress in surface science, 47, 137 (1998).

9. P. Sabatier. Ber. Deutchen Chem. Gesellschaft, 44, 1984 (1911).

10. R. Parsons. Trans. Farad. Soc., 54, 1053 (1958).

11. J. K. Nørskov, J. Rossmeisl, A. Logadottir, L. Lindqvist, J. R. Kitchin, T. Bligaard, and H. Jonsson.. J. Phys. Chem. B, 108, 17886 (2004).

12. M. C. Payne, M. P. Teter, D. C. Allan, T. A. Arias, and J. D: Joannopoulos. Rev. Mod. Phys., 64, 1045 (1992).

13. G. Kresse and J. Furthmuller, Phys. Rev. B, 54, 11169 (1996).

14. D. Vanderbilt. Phys. Rev. B., 41, 7892 (1990).

15. B. Hammer, L. B. Hansen, and J. K. Nørskov, Phys. Rev. B, 59, 7413 (1999).

16. N. Metropolis, A. W. Rosenbluth, M. N. Rosenbluth, A. H. Teller, and E. N. Teller. J. Chem. Phys., 21, 1087 (1953).

17. J. Rossmeisl, J. K. Norskov, C. D. Taylor, M. J. Janic and M. Neurock, J. Phys. Chem B, 101, 21833 (2006)

18. J. Clavilier. J. Electroanal. Chem., 107, 211 (1980).

19. J. Clavilier, R. Faure, G. Guinet, and R. Durand. J. Electroanal. Chem., 107, 205 (1980).

20. N. M. Markovic, B. N. Grur, and P. N. Ross. J. Phys. Chem. B, 101, 5405 (1997).

21. L. Blum, D. A. Huckaby, N. Marzari, and R. Car. J. Electroanal. Chem., 537, 7 (2002).

22. V. Stamenkovic, B. S. Mun, M. Arenz, K. J. J. Mayrhofer, C. A. Lucas, G. Wang, P. N. Ross, N. M. Markovic. Nature Materials, 6, 241 (2007).

23. V. R. Stamenkovic, B. Fowler, M. S. Mun, G. F. Wang, P. N. Ross, C. A. Lucas, M. N. Markovic, Science 315, 493 (2007).

24. V. Stamenkovic, B. S. Mun, K. J. J. Mayrhofer, P. N. Ross, M. N. Markovic, J. Rossmeisl, J. Greeley, J. K. Norskov, Ang. Chem. Int. Ed., 45, 2897 (2006).

25. G. S. Karlberg and G. Wahnström, J. Chem. Phys., 122, 195705 (2005). 